\title{
ESTUDO DA CORROSÃO DO AÇO AISI 304 UTILIZADO EM MATERIAIS PARA CROMATOGRAFIA GASOSA NA MEDIÇÃO DO ÁLCOOL NÃO QUEIMADO
}

\author{
Marina Scheiffer Nadolny ${ }^{1}$, Katia Cristine Da Costa Silva ${ }^{1}$, Valéria de Cassia \\ Macedo ${ }^{1}$, Renato Penteado ${ }^{1.2}$ \\ ${ }^{1}$ Institutos Lactec \\ ${ }^{2} \mathrm{P} \& \mathrm{~K}$ Consultoria \\ E-mails: marina.nadolny@lactec.org.br, katia.silva@lactec.org.br, \\ valeria.macedo@lactec.org.br, renato@lactec.org.br
}

\section{RESUMO}

A cromatografia gasosa (CG) é uma técnica amplamente utilizada na Química Analítica. Na área veicular é aplicada para medição do álcool não queimado (ANQ), proveniente da queima incompleta na câmara de combustão, preconizada pela NBR $15598 / 2008$.

Os Institutos Lactec constataram um problema de corrosão nos êmbolos das seringas utilizadas durante as análises do $A N Q$, provocando a quebra do êmbolo da seringa durante as injeções.

O objetivo do presente estudo foi identificar o tipo de corrosão que deteriorou o êmbolo da seringa e sugerir ações para solucionar o problema que, possivelmente, atinge demais laboratórios veiculares.

A amostra utilizada foi uma seringa para cromatografia gasosa, com aproximadamente um mês de uso, com capacidade para $10 \mu \mathrm{L}$. A análise foi feita no êmbolo fabricado com aço inox AISI 304, da família dos austeníticos, utilizando a técnica de Microscopia Eletrônica de Varredura (MEV), para identificação do tipo de material, de corrosão e da matéria orgânica incrustada na amostra.

Através da técnica de microscopia, foi possível identificar uma corrosão do tipo pite, em locais onde a passividade do material é rompida, originando-se na superfície e penetrando verticalmente no material.

O artigo propõe medidas para a mitigação do problema e mostra resultados obtidos após sua adoção.

\section{INTRODUÇÃO}

$\mathrm{Na}$ área veicular, o álcool não queimado (doravante denominado de ANQ) é resultado da combustão incompleta em motores a combustão. Quando um combustível (hidrocarboneto) queima completamente, o oxigênio do ar combina-se 
com o hidrogênio para formar água $\left(\mathrm{H}_{2} \mathrm{O}\right)$, e com o carbono para formar o dióxido de carbono $\left(\mathrm{CO}_{2}\right)$. Se o processo de queima do combustível não for completo, alguns dos átomos de carbono combinam-se com apenas um átomo de oxigênio, ao invés de dois, para formar monóxido de carbono (CO) [[1]].

No Brasil, a medição ANQ veicular deve ser realizada por meio da técnica de cromatografia gasosa e seguir os preceitos da norma brasileira NBR 15598/2008 [[2]].

As primeiras técnicas semelhantes à cromatografia gasosa surgiram em cerca de 1930, porém seu desenvolvimento somente foi acelerado com a introdução da cromatografia gás-líquido em 1952, por James e Martin [Erro! Fonte de referência não encontrada.], sendo aprimoradas com o passar dos anos e, atualmente, amplamente utilizadas na Química Analítica.

Este tipo de análise tem como característica do processo, a utilização de água como solvente, o que possivelmente contribui para a imersão de produtos secundários provenientes da combustão incompleta do veículo, assim como material particulado e gases dissolvidos.

A corrosão pode ocorrer em materiais metálicos ou não metálicos, através da interação com o meio, sendo por ação química ou eletroquímica, podendo também estar aliada a esforços mecânicos ou não, e ser agravada por organismos microbiológicos. Pode ser definida como sendo a deterioração do material em questão. [[4]]

No caso dos aços inoxidáveis, como o AISI 304, pertencente à família dos austeníticos, o material possui uma camada passiva, que se forma quando ele entra em contato com o oxigênio do ar ambiente, formando uma película de óxido de um determinado componente da liga. No caso do AISI 304, é formado óxido de cromo. Essa película é adquirida de maneira mais estável em ligas com mais de $12 \%$ de cromo. [[4]]

Os aços austeníticos são de baixo teor de carbono, ligados ao cromo com cerca de 16 a $26 \%$, e ao níquel com cerca de 6 a $22 \%$. São aços de boa soldabilidade, alta ductilidade, e considerados de grande resistência à corrosão, e adequados para trabalhar desde baixas temperaturas até $925^{\circ} \mathrm{C}$, e não são magnéticos. [5]

O níquel presente nesses aços serve para austenizá-los e acelerar a formação da camada passivante de óxido de cromo, assim como para aumentar a resistência mecânica do material [[4]].

Suas principais aplicações são em equipamentos para indústrias química, petroquímica, alimentícia e farmacêutica, além da construção civil e utensílios domésticos. [[5]]

Assim como muitos laboratórios de emissões veiculares brasileiros, o LEME, laboratório dos Institutos Lactec, também realiza com frequência a medição de ANQ e identificou um processo de corrosão do êmbolo das seringas utilizadas na técnica da Cromatografia Gasosa, quando realiza análise de ANQ. 
Como resultado do entupimento da seringa e sendo agravado pela corrosão, por diversas vezes houve o rompimento do êmbolo da seringa após a injeção de algumas amostras. Após o rompimento, foi possível observar uma corrosão no material do êmbolo, até então de característica desconhecida. Também, observouse uma incrustação de matéria proveniente do tipo de análise ou da amostra coletada.

Em função do problema ocorrido, foi necessário investigar sua causa e propor soluções para solucioná-lo ou mitigá-lo.

O objetivo do presente artigo é apresentar o resultado dos estudos realizados e suas conclusões.

\section{METODOLOGIA}

Para a execução do teste em laboratório, o veículo é posicionado com as rodas propulsoras em um dinamômetro de chassis, que aplica cargas de velocidade, aceleração, tempo de condução e freqüências de partidas, simulando condições de utilização em estrada. Durante o teste o veículo deve ser conduzido de acordo com um ciclo normatizado [[6]].

Durante o ciclo, o gás de escapamento do veículo, que em cada ensaio pode ser abastecido com combustível com diferentes concentrações de etanol, é coletado e borbulhado em água para a coleta de ANQ. Este tipo de análise contribui muito para o entupimento da seringa, pois além do álcool, vários outros produtos da combustão ficam submersos na água, assim como o material particulado. Esta amostra é injetada em cromatógrafo gasoso e analisada com um detector de ionização de chama (FID). O principal problema encontrado foi o entupimento da seringa com material proveniente da combustão. A corrosão é um agravante deste problema.

Verificou-se, também, que ocorre entupimento e quebra do êmbolo em seringas de marcas diferentes, com tempos médios de utilização semelhantes. Como resultado, concluiu-se que o problema não estava relacionado a um fornecedor, marca ou modelo específico, e sim às características da análise.

A Figura 1 apresenta a amostra utilizada para as análises. Nela é possível identificar as duas partes da seringa, com capacidade para $10 \mu \mathrm{L}$. O êmbolo está identificado com o número 1 , e o corpo da seringa, com o número 2. O êmbolo é a parte analisada pelo MEV, onde foi localizada a matéria incrustada e os sinais de corrosão. Na peça 2, o corpo da seringa, foi identificado o entupimento. 


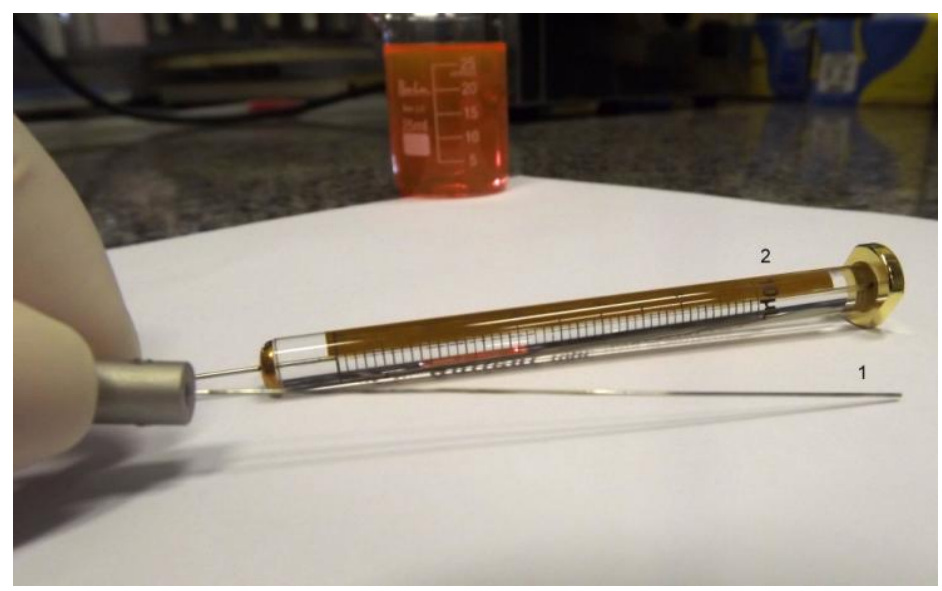

Figura 1 - Corpo da seringa e o êmbolo. Observa-se a parte escurecida no interior do êmbolo, marcado pelos produtos da combustão do veículo e da corrosão.

Fonte: os autores (2014)

As análises foram feitas utilizando a Microscopia Eletrônica de Varredura (MEV), que utiliza feixes de elétrons sobre a estrutura da amostra. Com o MEV é possível obter aumentos de 300.000 vezes ou mais quando se trata de materiais sólidos. Este equipamento difere do microscópio convencional, que obtêm aumentos de no máximo 2000 vezes, e também por sua aquisição rápida de informações sobre a composição do material sólido, e sua morfologia. Outra importante característica do MEV é a capacidade de ilustrar imagens tridimensionais, graças à sua profundidade de campo. [5].

A amostra utilizada para os testes foi o êmbolo de uma seringa de $10 \mu \mathrm{L}$, com aproximadamente um mês de uso. Durante o período de utilização, não foi aplicado qualquer método adicional de limpeza manual, pois o software de controle do equipamento possui uma rotina de limpeza que é realizada entre a injeção de cada amostra, realizada pelo injetor automático modelo Combi Pal. Inicialmente acreditava-se que este método fosse suficiente para a conservação da seringa. Posteriormente constatou-se que esta rotina tinha como objetivo evitar a contaminação líquida da amostra, mas não era suficiente para retirada de toda a matéria incrustada.

Para a solução do problema, primeiramente foi consultado o manual do fabricante buscando informações quanto ao tipo do material de composição do êmbolo. Não havendo este tipo de informação, uma amostra do material foi analisada pela técnica de Microscopia Eletrônica de Varredura (MEV) onde, a partir da emissão e interação de feixes de elétrons sobre a amostra, foi possível caracterizá-la sob o ponto de vista de sua organização estrutural [5]. Foram também capturadas informações da superfície da amostra, sem resíduos de incrustações, para identificação do tipo de material que compõe o êmbolo.

\section{RESULTADOS}

Por meio do MEV foi possível quantificar os principais componentes presentes na amostra e classificá-los tendo como referência uma tabela conhecida. No presente 
estudo, foi utilizada a Tabela 1 como comparativo para determinação da composição da amostra.

Tabela 1

\begin{tabular}{cc}
\hline Número AISI & 304 \\
\hline Número UNS & S30400 \\
\hline Composição & $0,08 \mathrm{C} \mathrm{.19} \mathrm{Cr} .9 \mathrm{Ni} .2,0 \mathrm{Mn}$ \\
\hline Ductilidade [\%AL em 50mm (2in)] & 40 \\
\hline Aplicações Típicas & $\begin{array}{c}\text { Equipamentos para processamento } \\
\text { químicos e de alimentos, vasos } \\
\text { criogênicos. }\end{array}$ \\
\hline
\end{tabular}

Fonte: [5]

Comparando os valores obtidos através da análise do MEV com os tabelados, constatou-se que o material do êmbolo é o aço AISI 304, pertencente à família dos austeníticos. A determinação se deu levando em consideração, principalmente, a concentração de Níquel e Cromo.

A Figura 2 mostra uma imagem da matéria orgânica, obtida pelo MEV, de uma incrustação no êmbolo. A análise do MEV na região do espectro 6 revelou a presença de $58,7 \%$ de carbono.

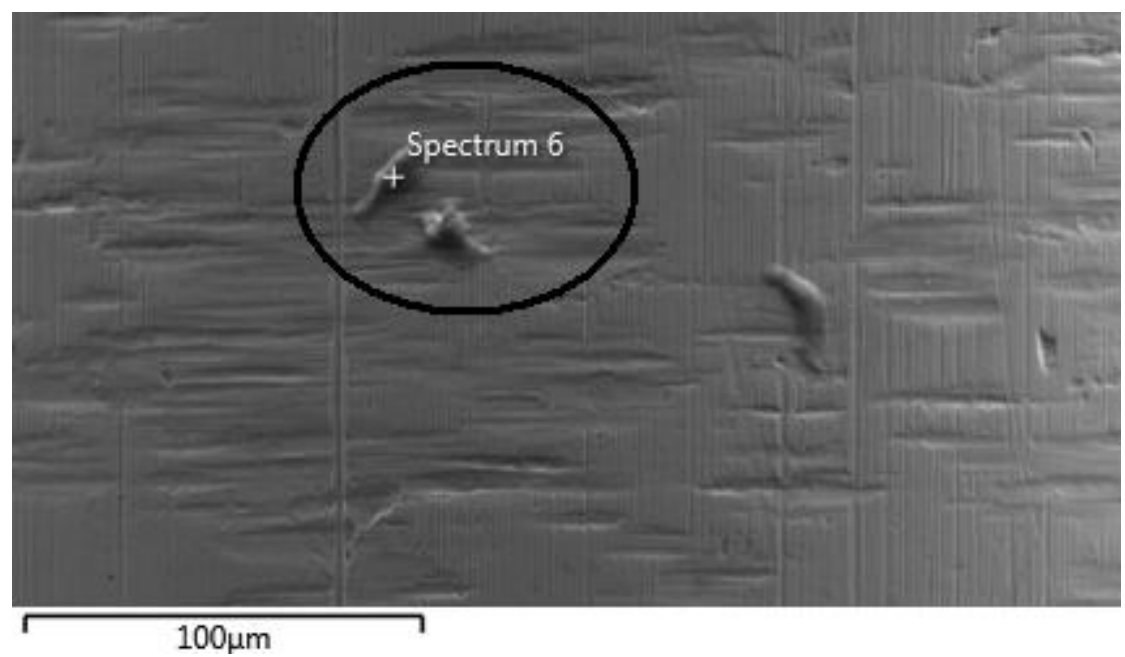

Figura 2. Incrustação no êmbolo da seringa.

Fonte: Os autores (2014)

O gráfico da Figura 3, mostra também a concentração de outros elementos além do carbono, que são considerados contaminantes, já que nesta análise o material não havia passado pelo tratamento de limpeza. 


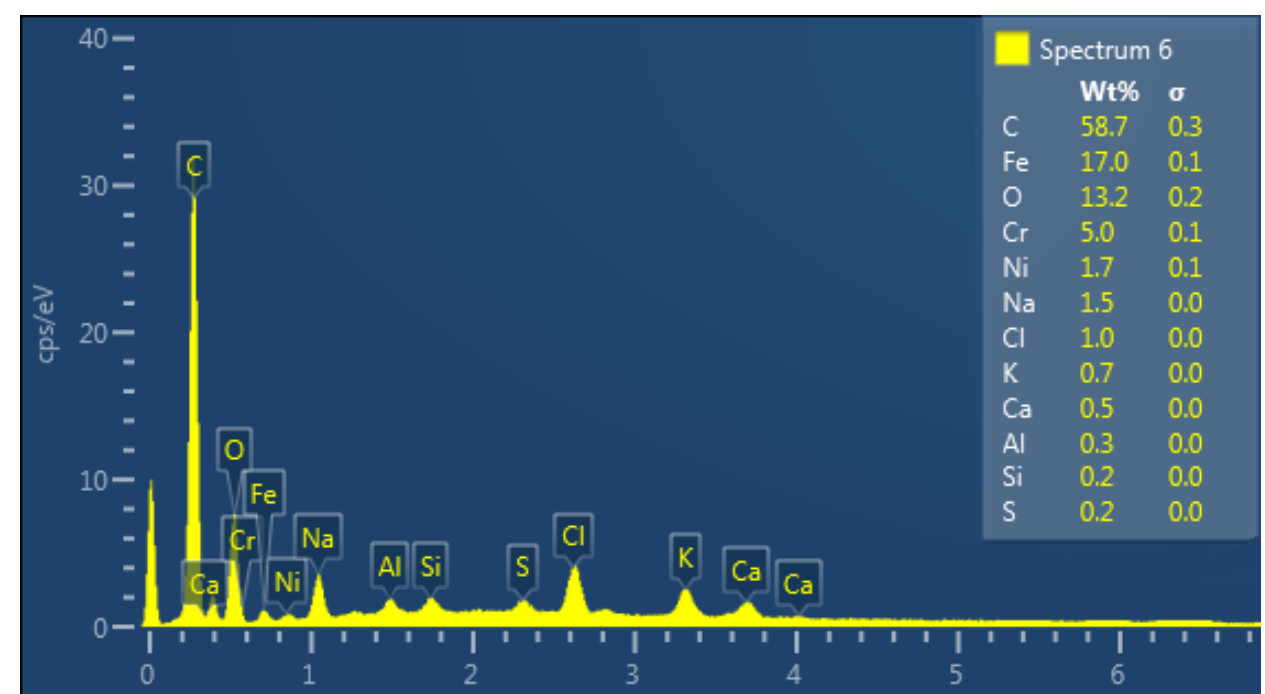

Figura 3 - Gráfico gerado pelo MEV com os picos correspondentes a cada elemento presente no local onde o espectro 6 foi capturado.

Fonte: os autores (2014)

As primeiras imagens do material foram obtidas sem limpeza prévia, para identificação da existência, ou não, de matéria orgânica incrustada na amostra, como mostrado na Figura 2. Após a identificação do tipo de material e a constatação de que havia existência de matéria orgânica incrustada, o êmbolo foi submetido a um tratamento pré-análise, sendo lavado primeiramente com solvente hexano, em ultrassom por cerca de cinco minutos. Em seguida a amostra foi submersa em acetonitrila no intervalo de 2 a 5 minutos, por 3 vezes, e enxaguada com água ultrapura por pelo menos 5 vezes. Após o método de limpeza, a amostra foi novamente submetida à análise do MEV, para determinação do tipo de corrosão presente na amostra.

A Figura 4 mostra um registro do MEV com aumento de 540 vezes, relativo à superfície do êmbolo da seringa durante o teste para determinação do material que o compõe. Na figura, pode se- observar duas regiões onde foram analisados os componentes. A Figura 5 apresenta um gráfico do espectro 2. Os valores obtidos foram avaliados comparativamente aos da Tabela 1 para determinação da composição do material. A resposta do MEV em formato de gráfico, com picos individuais correspondentes a cada componente dá a concentração em porcentagem de cada componente presente na amostra. 


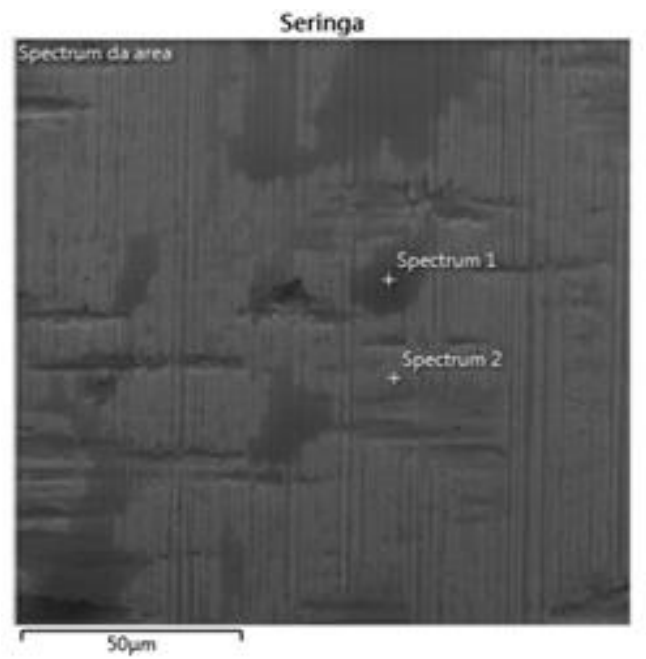

Figura 4 - Superfície do êmbolo durante o ensaio para determinação do material. da superfície do êmbolo. Aumento : $540 \mathrm{x}$

Fonte: os autores (2014)

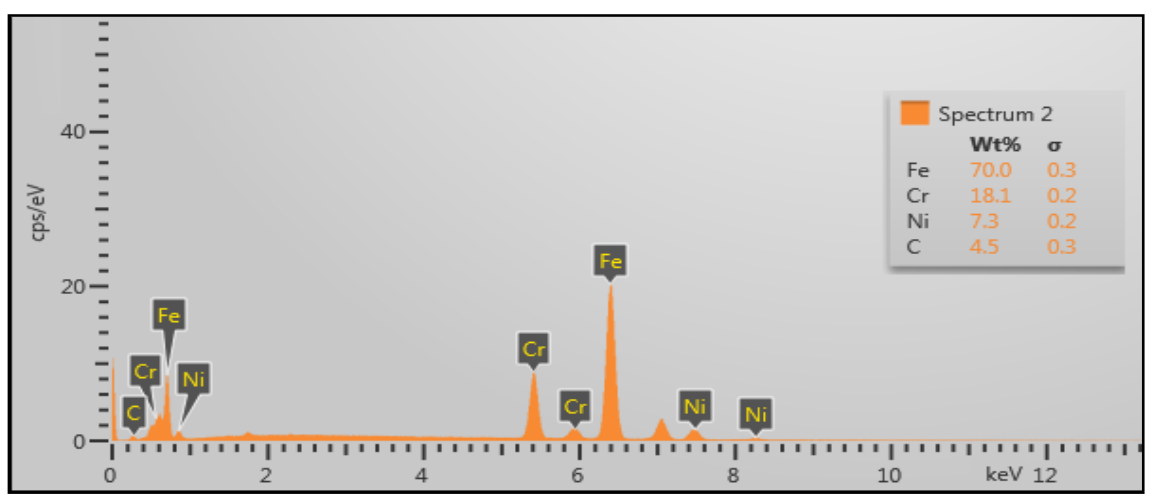

Figura 5: Espectro 2 gerado pelo MEV e utilizado para determinação do material da superfície do êmbolo.

Fonte: os autores (2014)

A Tabela 2 mostra as principais concentrações encontradas na amostra, segundo o gráfico da Figura 5. Os valores em porcentagem adquiridos foram comparados com a Tabela 1.

Tabela 2- Concentrações dos principais componentes encontrados na amostra.

\begin{tabular}{c|c|c} 
Elemento & Concentração Aproximada & $\%$ \\
\hline $\mathbf{C}$ & 1.03 & 4.53 \\
$\mathbf{C r}$ & 22.94 & 18.14 \\
$\mathrm{Fe}$ & 75.65 & 70.00 \\
$\mathbf{N i}$ & 7.30 & 7.33 \\
\hline Total: & & 100.00 \\
\hline
\end{tabular}

Fonte: Os autores (2014) 
Após a determinação da sua composição, o material foi submetido à análise do MEV para determinação do tipo de corrosão, com aumento de 40x, 258x e 540x.

As Figuras 6, 7 e 8 apresentam a amostra submetida à análise do MEV. A Figura 6 mostra uma imagem com aumento de 40x, onde se pode observar vários sinais de incrustações e de corrosão por toda extensão da amostra.

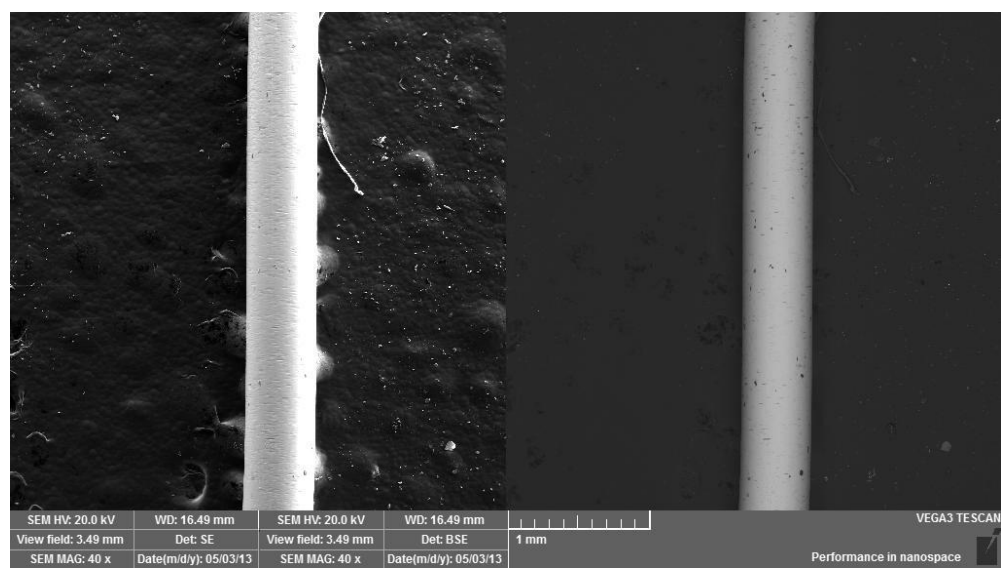

Figura 6 - Imagem do MEV relativa ao corpo do êmbolo, com aumento de $40 \mathrm{x}$ Fonte: Os autores (2014)

A Figura 7 mostra uma imagem com um aumento de 258x, onde se pode observar mais nitidamente as incrustações na parede da amostra, e os sinais de corrosão.

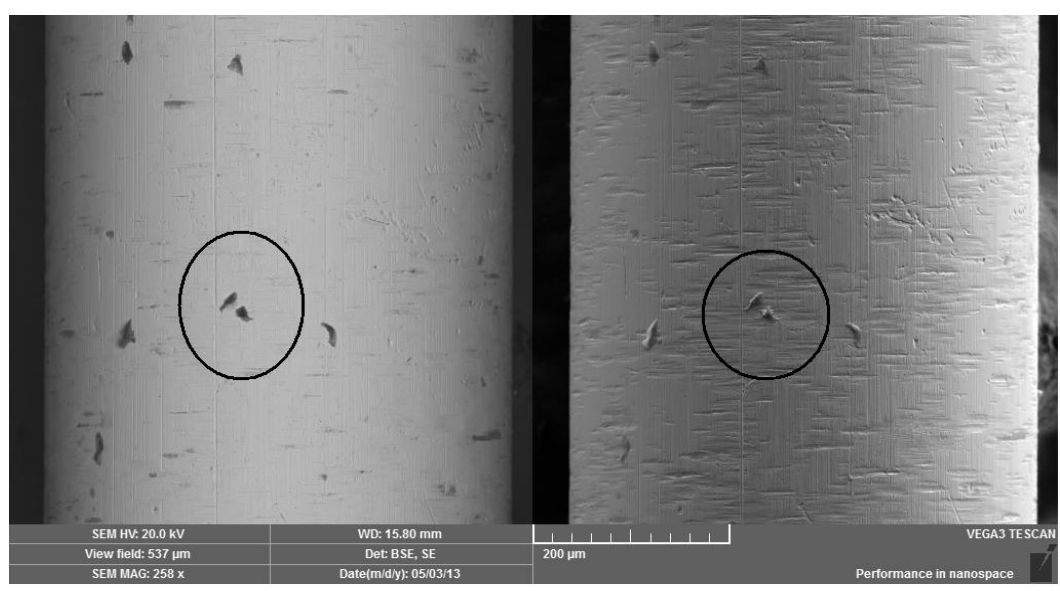

Figura 7 - Imagem do MEV relativa ao corpo do êmbolo, com aumento de $258 \mathrm{x}$ Fonte: Os autores (2014)

A Figura 8 mostra uma imagem com um aumento de $540 \mathrm{x}$, onde ficam evidenciados os sinais de corrosão, incrustações e de desgaste mecânico devido ao movimento do êmbolo ao percorrer seu curso no interior da seringa. As incrustações de matéria orgânica estão evidenciadas pelo número 1, e os sinais de corrosão do tipo pite, pelo número 2. 


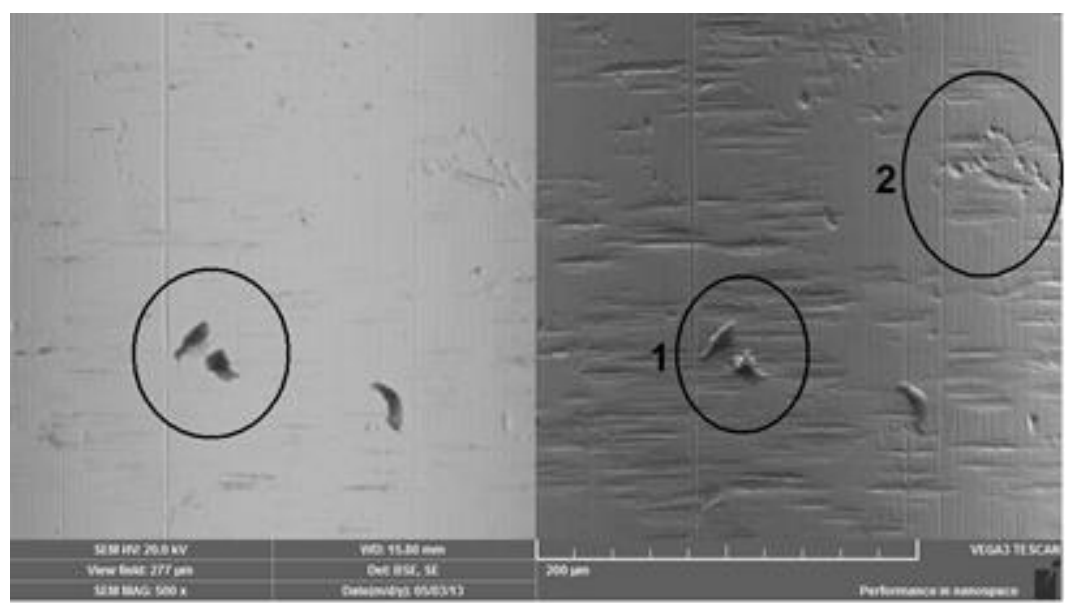

Figura 8 - Imagem do MEV relativa ao corpo do êmbolo, com aumento de 540x Fonte: Os autores (2014)

Com a aplicação da metodologia foi possível observar uma corrosão do tipo Pite, sinais de desgaste do êmbolo devido ao trabalho mecânico e incrustações de matéria orgânica, provavelmente provenientes da combustão incompleta do veículo. O Pite é um tipo de corrosão localizada que se caracteriza por orifícios de diâmetro pequeno e profundidade razoável, originando-se na superfície do material e penetrando verticalmente. Esta corrosão se origina, geralmente, em locais onde a passividade do material é rompida [3], seja por reações com o meio onde se encontra, ou por atrito, como possivelmente foi o caso da amostra em questão.

Um veículo emite material particulado- sólido não solúvel- que, entrando em contato com o êmbolo, que durante seu trabalho mecânico no momento das injeções, contribui para o desgaste da camada passiva do material e para o entupimento da seringa. A matéria orgânica incrustada no êmbolo é a principal causa do entupimento da seringa, assim como o material particulado e outros produtos da combustão que contribuem para o processo.

Pode-se observar também, que a formação da corrosão se deu na extensão do material até a marca de $7 \mu \mathrm{L}$. Isso pode estar relacionado com a formação microbiana proveniente da água de limpeza, que fica exposta ao meio ambiente durante toda a injeção das amostras numa operação que pode se estender pelo período 6 até 15 horas.

A limpeza da seringa é, usualmente, feita de forma automática e programável no cromatógrafo. A programação permite que seja feita uma série de análises, com diversas amostras, e o tempo requerido depende da quantidade de amostras analisadas.

Rodrigues et al. realizaram testes em amostras de aços inoxidáveis AISI 304 e AISI 316 , em solução de $\mathrm{NaCl}$ a $0,9 \%$, cujo objetivo foi analisar a influência de biofilmes microbianos no aumento da resistência a corrosão desses materiais. Os autores concluíram que a formação de pites sofre aumento na presença de microrganismos. [6]. A corrosão microbiana ocorre, usualmente, sob a presença de microrganismos, mais frequentemente com bactérias, podendo, no entanto também ocorrer na 
presença de fungos. Neste caso, um biofilme se forma quando os compostos orgânicos absorvidos na água são adsorvidos na amostra metálica. [3]

Para mitigar o problema de quebra do êmbolo da seringa foi proposto um método de limpeza manual simples e eficaz para prevenir a incrustação de matéria orgânica, o que fez com que a seringa não entupisse na mesma frequência anterior. Esta técnica de limpeza diária é constituída pela retirada da incrustação de maneira mecânica, e limpeza do corpo da seringa, somente com água após a limpeza do êmbolo, a seringa é recolocada novamente no injetor depois de seca. No caso dos Intitutos Lactec, foi criado um documento interno, onde são registradas as limpezas da seringa.

\section{CONCLUSÃO}

O uso da técnica de microscopia eletrônica de varredura foi adequado para a determinação do tipo de corrosão ao qual está sujeito o êmbolo. Os resultados oriundos do MEV viabilizaram a identificação das causas que provocam entupimento do êmbolo e seu rompimento, assim como contribuíram para a determinação do material que o compõe.

O problema de quebra do êmbolo de seringa utilizada em ensaios de cromatografia gasosa foi mitigado, aumentando assim a vida útil da seringa, que tinha duração média de 1 mês. Após a adoção das medidas de limpeza do corpo da seringa, a vida útil da seringa passou para, no mínimo 5 meses.

A mitigação do problema de quebra de êmbolos das seringas reduziu o tempo das análises e os custos de reposição de material.

\section{AGRADECIMENTOS}

Os autores agradecem ao Ministério da Ciência e Tecnologia e ao CNPq (Conselho Nacional de Desenvolvimento Científico e Tecnológico) pelo incentivo recebido com a aplicação da Lei 8010/90. Agradecem também à equipe do Laboratório de Emissões Veiculares dos Institutos Lactec, onde foram realizados os ensaios.

\section{REFERÊNCIAS}

[1] SILVA, K.C.C. Estudos de Emissões Legisladas, Álcool não Queimado e Potencial de Formação de Ozônio de um Veículo Leve Bicombustível. Dissertação de Mestrado, Curitiba, 2014.

[2] ABNT. NBR 15598: Veículos rodoviários automotores leves - Determinação de etanol não queimado contido no gás de escapamento por Cromatografia Gasosa - Método de Ensaio. Rio de Janeiro, 2008.

[3] COLLINS, Carol H, BRAGA, Gilberto L, BONATO, Pierina S. Fundamentos da cromatografia. Unicamp, 2006

[4] GENTIL, Vicente. CORROSÃO. LTC - Livros Técnicos e Científicos. Rio de Janeiro, 1982 
[5] CALLISTER JR., William D. - Ciência Engenharia de Materiais - Uma Introdução - 8 ad. LTC - Livros Técnicos e Científicos, 2012

[6] ABNT. NBR 6601: Veículos rodoviários automotores leves - Determinação de hidrocarbonetos, monóxido de carbono, óxidos de nitrogênio, dióxido de carbono e material particulado no gás de escapamento: NBR 6601. Rio de Janeiro, 2012.

[7] BREDA, Eymard de Meira. Água Grau Reagente para Laboratório e Outros Fins Especiais. Setembro/2001

[8] DEDAVID, Berenice Anina, GOMES, Carmem Isse, MACHADO, Giovanna. Microscopia Eletrônica de Varredura: Aplicações e preparação de amostras. Porto Alegre. EDIPUCRS, 2007 -

[9] RODRIGUES, Lorena Raphael, NICOLIN, Viviane Azambuja Favre, SOARES, Ninive, KORRES, Adriana Márcia Nicolau. Estudo do Efeito de Microorganismos em Aços Inoxidáveis AISI 304 e 316, VIII Jornada de Iniciação Científica, Desenvolvimento Tecnológico e Inovação do Ifes, 2013 